\title{
A PERFECTIBILIDADE SEGUNDO ROUSSEAU ${ }^{1}$
}

\author{
Mauro Dela Bandera Arco Júnior ${ }^{2}$
}

Resumo: O homem do puro estado de natureza começa sua existência "por funções puramente animais". De fato, o esforço de Rousseau na primeira parte do Discurso sobre a desigualdade consiste em quase "animalizar" o ser humano, tornando-o incapaz de realizar certos tipos de operações que o homem social ou socializado (dotado de um aparelho mental já desenvolvido) pode efetuar. No entanto, apesar de animalizado, o homem conserva sua dignidade própria e sua natureza exclusiva. O autor jamais reduz o comportamento humano ao animal. O objetivo do presente artigo é investigar o caráter desta natureza exclusiva e mostrar que, ao contrário do que sustentam alguns intérpretes, a perfectibilidade (signo de distinção humano) já atua no puro estado de natureza. Nesse sentido, não podemos encará-la como uma simples virtualidade nem como uma faculdade em potência.

Palavras-chaves: Rousseau - Perfectibilidade - Humanidade - Animalidade.

\section{$* * *$}

Apesar de Rousseau ratificar a opinião de alguns filósofos - dentre eles Montaigne, que sustentava "que há mais diferença entre um homem e outro do que entre um homem e um animal"3 -, sugerindo uma espécie de monismo anticartesiano, é preciso ressaltar que, de acordo com suas reflexões, existem sim predicados exclusivos aos seres humanos que acabam por inscrever sua filosofia em um dualismo - diferente, porém, do dualismo cartesiano. Assim como tantos outros autores, como Condillac e Buffon, Rousseau é partidário da hipótese da descontinuidade entre a animalidade e a humanidade. Em sua obra, o humano aparece em oposição aos não humanos, como um ser dotado de uma dignidade própria.

Para Rousseau, a liberdade e a perfectibilidade são as duas características metafísicas que fazem a distinção entre homens e animais: os homens são agentes livres (sua natureza não se inscreve em disposições fixas) e perfectíveis, ao passo que os animais são condenados a seguir o instinto próprio de sua espécie e a permanecer sempre idênticos a si mesmos.

\footnotetext{
${ }^{1}$ Uma versão preliminar deste artigo foi apresentada em nossa tese de doutorado, A origem da alteração e a alteração de origem: antropologias de Rousseau, defendida em 2018 na FFLCH/USP.

2 Doutor em Filosofia pela USP. E-mail: maurodelabandera@yahoo.com.br

${ }^{3}$ ROUSSEAU, "Discours sur l'origine de l'inégalité", p. 141; MONTAIGNE, Essais, p. 311.
} 
Não podemos confundir perfectibilidade com liberdade, tal como fizera Derrida nas páginas da Gramatologia ${ }^{4}$, tampouco podemos dissociar de forma peremptória essas duas noções, tal como sustentara Goldschmidt ${ }^{5}$. Segue-se que a perfectibilidade deve ser encarada como o índice ou o sintoma da liberdade. Nesta direção, Guichet afirma que "a perfectibilidade aparece ao menos ligada à liberdade, mesmo que não seja idêntica a ela" .

Caberia, pois, explicar o que são afinal a liberdade e a perfectibilidade. Não obstante, focaremos nossa investigação na elucidação da ideia de perfectibilidade. Nesta perspectiva, analisaremos no presente artigo o momento em que essa faculdade entra em cena na história do desenvolvimento humano, seja individual seja coletivo. Nossa hipótese é que a perfectibilidade se faz presente e está ativa mesmo no puro estado de natureza. Tal hipótese questiona, assim, a leitura corrente de acordo com a qual a perfectibilidade permaneceria em estado virtual ou em potência no puro estado de natureza.

Ao contrário da liberdade, centro absoluto, a perfectibilidade inscreve-se num plano relativo, pois encontra-se submetida ao mundo e ao tempo. Não se trata de uma faculdade ofensiva que empreenda uma iniciativa, mas antes uma faculdade defensiva ou reativa que entra em cena para responder às provocações exteriores. Para o autor, "os progressos do espírito" humano (tomados aqui no âmbito coletivo) são sempre "proporcionais às necessidades que os povos haviam recebido da natureza ou às quais as circunstâncias os haviam sujeitado e, por conseguinte, às paixões que os levaram a atender tais necessidades"7. A (re)ação está, logo, inteiramente condicionada às necessidades que os homens possuem e às circunstâncias nas quais eles se inserem. Sem a perfectibilidade, eles certamente sucumbiriam, dado que para sobreviver precisam vencer constantemente as alterações do meio ambiente, as condições adversas de existência (sempre renovadas e alteradas) e os obstáculos que a natureza lhes impõe. Em resumo, a perfectibilidade é "a faculdade de aperfeiçoar-se; faculdade essa que, com a ajuda das circunstâncias, desenvolve sucessivamente todas as outras"

Esta faculdade das faculdades possibilita o desenvolvimento e a atualização de todas as demais, anteriormente em estado virtual. A razão, a moralidade, o domínio do fogo, a sociabilidade, a linguagem e tantas outras coisas aparecem gradativamente no cenário histórico, no momento exato em que se tornam necessários, is to é, quando exigidos pelas circunstâncias. Ela reside, entre nós, tanto na espécie quanto no indivíduo; é constatada no homem, "animal livre, tanto no nível ontogênico quanto filogênico"”.

\footnotetext{
4 “A liberdade é, portanto, a perfectibilidade” (DERRIDA, De la Grammatologie, p. 260).

5 “Ela não é nem invenção, nem reflexão, não é razão, tampouco é liberdade. É somente a condição prévia e formal que torna possível todas essas faculdades" (GOLDSCHMIDT, Anthropologie et politique, p. 288, grifo nosso).

${ }^{6}$ GUICHET, Rousseau: l'animal et l'homme, p. 252.

${ }^{7}$ ROUSSEAU, "Discours sur l'origine de l'inégalité", p. 143.

${ }^{8}$ ROUSSEAU, "Discours sur l'origine de l'inégalité", p. 142 (grifo nosso).

${ }^{9}$ ROBERT, "Rousseau et les Pongos", $₫ 11$.
} 
Dito isto, é corrente pensar que a perfectibilidade permanece sem emprego ou inativa no puro estado de natureza ${ }^{10}$. De acordo com as palavras de Victor Goldschmidt, ela aparece apenas "em potência" no homem do primeiro estado de natureza, permanecendo assim em um "estado de simples virtualidade"11. Faltam necessidades que possam desencadear o mecanismo, dizem alguns comentadores, e o próprio Rousseau assim o sugere:

depois de haver mostrado que a perfectibilidade, as virtudes sociais e as outras faculdades que o homem natural recebera em potência nunca poderiam desenvolver-se por si sós, que para tanto necessitavam do concurso fortuito de várias causas estranhas, que poderiam jamais nascer, e sem as quais ele teria permanecido eternamente em sua condição primitiva, resta-me considerar e relacionar os diferentes acasos que puderam aperfeiçoar a razão humana, deteriorando a espécie, tornar mau um ser ao torná-lo sociável e, de uma época tão recuada, trazer afinal o homem e o mundo ao ponto em que os vemos. ${ }^{12}$

No entanto, mesmo distante das circunstâncias que, rompendo o padrão ordinário da vida, solicitam ou exigem a perfectibilidade de uma maneira bem mais potente e premente, o simples ordinário do estado de natureza e a vida puramente natural já constituem uma circunstância constante e, por isso, requerem sim a perfectibilidade. De acordo com JeanLuc Guichet, que segue a esse respeito a interpretação de Roger Masters ${ }^{13}$ e outros comentadores (Beyssade e Robert), "a perfectibilidade parece funcionar a partir do estado de natureza mesmo se pouco visível" 14 .

10 STAROBINSKI, Jean-Jacques Rousseau: a transparência e o obstáculo, seguido de sete ensaios sobre Rousseau, pp. 154, 225,287 e 410.

11 GOLDSCHMIDT, Anthropologie et politique, p. 289.

12 ROUSSEAU, "Discours sur l'origine de l'inégalité", p. 162.

13 "A perfectibilidade, portanto, operou efetivamente - e não apenas em potência - no puro estado de natureza.” (MASTERS, The Political Philosophy of Rousseau, p. 150).

${ }^{14}$ GUICHET, Rousseau: l'animal et l'homme, p. 252. Thomas Robert pensa de forma similar: a perfectibilidade já opera e está em ato desde o primeiro estado de natureza. "A essência do homem, representada pela liberdade e pela perfectibilidade, está sempre em ato, ao menos em uma acepção mínima, sendo a aprendizagem do instinto a melhor prova disso" (ROBERT, "Rousseau et les Pongos", \ 11). E também Jean-Marie Beyssade: "conviria distinguir entre uma ausência total de desenvolvimento que deveria (com a animalidade dos grandes macacos antropoides) se identificar com o instinto animal e um primeiro desenvolvimento, rudimentar sem dúvida, mas pelo qual os homens 'se elevariam até o instinto dos bichos', o que não é mais instinto, mas já aperfeiçoamento. [...] Desde a primeira parte e antes da 'primeira revolução', antes da idade das cabanas e seus múltiplos efeitos sobre o espírito e os corações, o modelo do puro estado de natureza não é de forma alguma de total imobilidade" (BEYSSADE, "Rousseau et la pensée du développement: Facultés virtuelles et développement", p. 206). "Poder-se-ia buscar na perfectibilidade o princípio unitário de uma antropologia rousseauísta do desenvolvimento. Trata-se, de fato, de um caractere presente tanto no indivíduo quanto na espécie e, parece, não é e nunca poderia ser virtual ou em potência: como uma aptidão para adquirir (na ocasião da experiência) tudo o que se possa ter a partir do nada e da ausência de instinto, a perfectibilidade é por definição atual e suscetível de operar desde o primeiro estado de natureza. É por isso que, desde a primeira parte do Discurso sobre a desigualdade, o homem selvagem é menos 'entregue pela natureza unicamente ao 
O homem precisou aprender a vencer as dificuldades. O exemplo da alimentação (o momento em que o homem come pela primeira vez) é aqui bastante esclarecedor. Rousseau considera que foi necessário que o homem compreendesse minimamente sua situação (não sua condição de ser humano, mas de vivente e ser sensível) e a partir disso encontrasse formas de subsistência. "O primeiro sentimento do homem foi o de sua existência e seu primeiro cuidado, o de sua conservação. As produções da terra forneciam-lhe todos os socorros necessários, o instinto levou-o a fazer uso delas"15.

Rousseau fala de instinto ou de uma espécie de comportamento maquinal, mas poderíamos pensar em uma imitação do comportamento animal (o que também expressa um aprendizado, tanto do homem que imita quanto do animal para adquirir ou se apropriar do comportamento próprio de sua espécie) ou outra coisa equivalente. No Emílio, o autor diz sobre os animais o que, no segundo Discurso, poderíamos estender aos homens do puro estado de natureza: "eles têm sentido, é preciso que aprendam a fazer uso deles; têm necessidades, é preciso que aprendam a satisfazê-las; é preciso que aprendam a comer, a andar, a voar. [...] Tudo é instrução para os seres animados e sensíveis" ${ }^{16}$. Como bom leitor de Condillac (para o qual, no Tratado dos animais, é preciso aprender e formar até mesmo o instinto), Rousseau considera que o homem precisou seriamente "aprender a vencer" as dificuldades.

Contudo, não se trata aqui de afirmar a existência de certa "aprendizagem" no estado de natureza, tal como defendera Goldschmidt: "uma aprendizagem limitada que não diferiria essencialmente daquela que os animais são capazes"17. Os processos de aquisição de conhecimentos elementares dos homens e dos animais seguem, poder-se-ia dizer, os mesmos princípios. No entanto, salientamos, existem também peculiaridades importantes em cada um deles. Se o princípio não racional do amor-de-si garante ao homem e aos animais a preservação e a busca pelos meios de satisfazer suas respectivas necessidades, sendo todas as suas ações fruto de uma experiência, a ação humana se distingue da ação animal por basearse na perfectibilidade e em uma escolha feita a partir da observação e da imitação dos instintos dos outros (animais e humanos) a fim de satisfazer o amor-de-si na busca da autopreservação.

Trata-se, no homem, da própria perfectibilidade operando a partir de uma polivalência, adquirida por meio da imitação humana do comportamento dos demais seres. Esta imitação se deve, sobretudo, à ausência de um verdadeiro instinto próprio ao homem, ao contrário do que se passa em cada espécie animal, retendo-a sempre igual a si mesma. Essa ausência é o que torna propriamente concebível a perfectibilidade do homem e que significa sua liberdade, isto é, a inexistência de essência rígida.

instinto' do que 'compensado daquele que talvez lhe falte, por faculdades capazes primeiro de o substituírem e depois de elevá-lo muito acima do que era': se o tempo deixou o homem 'com toda a grosseria das primeiras épocas', não é que a perfectibilidade fosse ainda simplesmente virtual, porque seus efeitos, limitados a uma vida de homem, não passaram de geração em geração" (BEYSSADE, "Rousseau et la pensée du développement: Facultés virtuelles et développement", pp. 203-204).

${ }^{15}$ ROUSSEAU, "Discours sur l'origine de l'inégalité", p. 164.

16 ROUSSEAU, “Émile ou de l'éducation”, p. 281.

${ }^{17}$ GOLDSCHMIDT, Anthropologie et politique, p. 260. 
Rousseau havia apresentado suas pesquisas como "raciocínios hipotéticos e condicionais", simples "conjecturas tiradas apenas da natureza do homem e dos seres que o cercam" ${ }^{18}$. Esta coabitação entre homens e animais é essencial para a argumentação do autor: os homens dispersos entre os animais "observam, imitam sua indústria e se elevam assim até o instinto dos bichos, com a vantagem que cada espécie tem somente o seu próprio e que o homem, não tendo talvez nenhum que lhe pertença, se apropria de todos" ${ }^{19}$. Em um primeiro momento, o homem é menos que o animal ${ }^{20}$, posteriormente, por meio da observação e da imitação, ele se iguala ao animal para, finalmente, ultrapassá- $\mathrm{l}^{21}$. Mesmo se concordarmos que a esfera animal constitui durante muito tempo o único horizonte do homem do puro estado de natureza, é preciso compreender que este possui uma essência diferente daquela do animal e que esta essência começa a revelar-se exatamente pelo mimetismo. Nas palavras de Guichet, "o homem começa por esconder-se atrás do animal”. Mas o véu pelo qual a especificidade humana "se dissimula é precisamente o que a revela"22.

Não podemos confundir o mimetismo realizado pelos animais com aquele produzido pelos seres humanos. Ainda que cada animal necessite aprender de forma espontânea e natural para desenvolver-se e apropriar-se de todas as potencialidades intrínsecas à sua espécie, este procedimento o aproxima de si mesmo e, portanto, não se abre à alteridade. Contrariamente, o homem exerce a imitação a fim de sair de si em direção à alteridade e ao não idêntico. "Ao mesmo tempo em que se aproxima dos animais por meio da imitação, ele marca seu afastamento irredutível, pois atesta assim sua capacidade de sair de si mesmo em direção ao animal, que, por sua vez, permanece encerrado em si mesmo, apesar de dar a aparência de se afastar de si por meio do mimetismo"23. De um lado, o homem se mostra totalmente imerso na natureza e semelhante aos animais, uma vez que mimetiza seus comportamentos; de outro, ele desvela sua diferença como portador de uma natureza própria. Portanto, o homem do estado de natureza que se identifica com o animal por meio da imitação já é, paradoxalmente, um homem, pois expressa o predicado particular de seu ser.

Observar, imitar - mas não de maneira passiva e mecânica -, elevar-se: há nessas operações outra coisa que não a simples animalidade, a saber, uma capacidade de sair de si, de superação, que excede a pura aprendizagem animal, que consiste apenas no ajustamento o mais cerrado possível a seu

${ }^{18}$ ROUSSEAU, "Discours sur l'origine de l'inégalité", p. 133 (grifo nosso).

${ }^{19}$ ROUSSEAU, "Discours sur l'origine de l'inégalité", p. 135.

${ }^{20}$ É interessante citar uma passagem de La Mettrie: "apesar de todas estas prerrogativas do homem sobre os animais, é fazer-lhe uma honra posicioná-lo na mesma classe. Até certa idade, ele é mais animal do que eles, porque possui menos instinto quando nasce” (LA METTRIE, L'homme-Machine, p. 173).

${ }^{21}$ Nas palavras de Radica, “o homem, graças a seu mimetismo, torna-se superior aos animais que ele imita, pois pode imitá-los todos e também multiplicar seu poder acumulando em uma única pessoa habilidades corporais diferentes e complementares que nenhum animal poderia juntar" (RADICA, L'bistoire de la raison, p. 77).

22 GUICHET, Rousseau: l'animal et l'homme, p. 274.

${ }^{23}$ GUICHET, Rousseau: l'animal et l'homme, p. 276. 
próprio corpo, ao funcionamento de seus sentidos e a seu meio; uma adesão mais forte, portanto, inversa a qualquer tomada de distância. ${ }^{24}$

Guichet ainda afirma:

a imitação humana acessa outra ordem, diferente da imitação animal, mesmo que ela encontre sua primeira raiz nesta última. Ao mesmo tempo, expressa a natureza no homem e, já, a natureza do homem - por seu caráter ilimitado e sua diferença em relação à imitação nos animais, que se apegam a um modelo biologicamente semelhante, o que é o oposto de qualquer afastamento (arrachement) de si. A imitação é uma faculdade mediana e mediadora em todos os aspectos; é a primeira e discreta companheira da perfectibilidade, sua primeira forma de atualização verdadeira, compartilha com ela a função de articulação geral entre natureza e cultura, mas concentrase primeiro na relação entre o homem e o animal e, num segundo momento, abre-se para a relação de homem a homem. A diferença do homem consiste, antes de tudo e paradoxalmente, em se dispersar na multiplicidade da referência animal. [...] A imitação mostra que, na confusão primeira com a natureza, a especificidade humana já está em ação, bem como a natureza no homem é imediatamente habitada pela natureza do homem. De modo inverso, paradoxalmente, essa natureza do homem não pode ser plenamente ela mesma, isto é, humanidade, a menos que ela integre a natureza no homem, isto é, de forma precisa, a animalidade. ${ }^{25}$

Vejamos alguns exemplos e passagens sobre a imitação na obra de Rousseau, a fim de atestar e melhor compreender o funcionamento dessas manifestações embrionárias da perfectibilidade. No Princípio da melodia, lemos um trecho que fala da natureza imitativa do ser humano: ignoramos, nas palavras de Rousseau, "se existe algum tipo de grito" que seja próprio ao homem.

Em compensação, nós o conhecemos como um animal imitador que não tarda a se apropriar de todas as faculdades que ele pode extrair dos exemplos dos outros animais. Ele poderá então, de início, imitar os gritos daqueles que o cercam, e segundo as diversas espécies que habitam cada rincão, os homens, antes mesmo de possuírem línguas, puderam ter gritos diferentes de uma região à outra. ${ }^{26}$

${ }^{24}$ GUICHET, Rousseau: l'animal et l'homme, p. 253.

25 GUICHET, Rousseau: l'animal et l'homme, p. 276.

${ }^{26}$ ROUSSEAU, "Du Principe de la mélodie", p. 448. O texto a Origem da melodia, presente no quinto volume da Pléiade e editado por Marie-Élisabeth Duchez, é um fragmento do manuscrito "Du Principe de la mélodie ou réponse aux erreurs sur la musique". Foi Duchez quem o fragmentou e o nomeou (DUCHEZ, "Principe de la Mélodie et Origine des langues: un brouillon inédit de Jean-Jacques Rousseau sur l'origine de la mélodie”). 
No segundo Discurso, podemos destacar três exemplos da imitação, quais sejam: o exemplo da alimentação do gato e do pombo, empregado por Rousseau para elucidar a noção de liberdade; os primeiros agrupamentos humanos e as associações livres que não obrigavam ninguém e não duravam mais do que a necessidade passageira que os formavam; e, por fim, o exemplo das crianças asselvajadas (homo ferus), na nota III, que andam como os quadrúpedes.

No exemplo da alimentação do homem no estado de natureza, o homem pode transitar entre dietas possíveis (da dieta herbívora para uma onívora ou, eventualmente, carnívora); o pombo e o gato, em contrapartida, não são capazes de realizar essa mudança alimentar. É muito plausível que essa transição no homem tenha sido engendrada pela imitação dos hábitos alimentares de um animal predador e, por conseguinte, pela perfectibilidade. Nesse sentido, o regime vegetariano apresentado nas notas do Discurso como paradigmático é apenas um caso entre tantos outros possíveis do comportamento humano. O homem natural pode perfeitamente dele se afastar e encontrar circunstâncias que lhe exijam desenvolver um novo regime ou simplesmente imitar os animais de hábitos carnívoros.

Sobre os agrupamentos esporádicos e as associações livres, é também plausível pensar que foram os animais gregários, como os macacos, que sugeriram ao homem as vantagens destes agrupamentos efêmeros: "é fácil compreender", nos diz Rousseau, "que tal relacionamento não exigia uma linguagem muito mais refinada do que a das gralhas ou dos macacos, que se agrupam quase do mesmo modo"27.

Sobre os asselvajados, por sua vez, vale a pena citar toda a passagem.

Há diversos exemplos de homens quadrúpedes, e eu poderia citar, entre outros, o da criança que foi encontrada em $1344^{28}$, perto de Hesse, onde fora

\footnotetext{
No entanto, a intervenção editorial de Duchez traz consigo sérios problemas de caráter filológico e gera muitos mal-entendidos. Por isso, preferimos nos valer aqui da edição de Wokler.

${ }^{27}$ ROUSSEAU, "Discours sur l'origine de l'inégalité", p. 167 (grifo nosso).

${ }^{28}$ Há aqui uma divergência entre os pesquisadores. Lucien Malson, em seu livro Les enfants sauvages, insere o caso da criança-lobo de Hesse, em 1344, tal como encontramos na nota de Rousseau. Malson cita ainda o caso da criança-lobo de Wetteravie, também de 1344. Mas o trabalho de Lucienne Strivay, Enfants sauvages, cataloga no período três casos de crianças-lobos (1304, 1341 e 1344), sendo que os dois primeiros (1304 e 1341) se deram em Hesse, Alemanha, e o último é o mesmo caso da criança-lobo de Wetteravie (1344), próximo à floresta de Hardt, também na Alemanha. Tenderíamos a crer em um erro de Strivay, pois quando ela analisa o caso da criança de Hesse, encontrada em 1304, utiliza os argumentos de Philippe Camerarius, que data o caso em 1344 e cuja descrição está muito próxima daquela feita, posteriormente, por Rousseau. A autora afirma que Camerarius "evoca assim [...] a criança-lobo de Hesse, capturada em 1344 por caçadores e que fora oferecida como espetáculo à corte de Henrique, príncipe dessa região. Esse menino que, 'de acordo com suas próprias palavras', fora rapinado pelos lobos aos três anos de idade e deve ter ficado cinco anos entre eles, sempre fora bem tratado. Ele havia se beneficiado das melhores partes na divisão da caça e do aconchego da alcateia ao redor dele no frio, no poço de uma cova expressamente disposta com folhas e grama secas. Ele tinha aprendido com eles 'a rastejar com as mãos e os pés e a correr com eles, tantas vezes que, deste exercício, ele acabou imitando sua velocidade e fazia os maiores saltos'. As pernas embainhadas de talas de madeira, forçaram-lhe a endireitar-se, 'à maneira dos homens'. Mas a criança frequentemente repetia que preferia ficar em contato com
} 
nutrida pelos lobos, e que dizia depois na corte do príncipe Henrique, que, não fosse este, teria preferido voltar para junto deles a viver entre os homens. Adquirira de tal modo o hábito de andar como esses animais que foi preciso lhe amarrar peças de madeira que a forçassem a manter-se em pé e equilibrando-se em ambos os pés. Aconteceu o mesmo com a criança encontrada em 1694, nas florestas da Lituânia, e que vivia com os ursos. Não dava, diz Condillac, nenhum sinal de razão, caminhava com os pés e as mãos, não possuía nenhuma linguagem e formava sons que em nada se assemelhavam aos do homem. O pequeno selvagem de Hanôver, que foi conduzido para a corte da Inglaterra, teve todos os sofrimentos do mundo ao se sujeitar a caminhar sobre os dois pés; e encontra-se, em 1719, dois outros selvagens nos Pireneus, que corriam pelas montanhas à maneira de quadrúpedes. $^{29}$

Em resumo, Rousseau sustenta que uma criança abandonada na floresta e alimentada por um animal seguirá, por meio da imitação, o exemplo de sua provedora e, por não possuir referências sobre o comportamento humano, para realizar comparações, não conseguirá por si só vislumbrar a possibilidade do bipedismo.

Notamos também, no início da segunda parte do Discurso, alguns progressos e aquisições. De acordo com a cronologia apresentada no livro, algumas aquisições de técnicas e instrumentos (o arco, as flechas, a linha, o anzol, o fogo, etc.) entram em cena, antes mesmo de qualquer socialização humana. Embora sem comunicação, estas aquisições conheceram, podemos dizer, certa transmissão e veiculação explicadas exclusivamente pelo jogo da observação e da imitação, isto é, da perfectibilidade. Nesse período, ao contrário do que afirma o autor ao final da primeira parte, nem tudo morre necessariamente com o seu

os lobos" (STRIVAY, Enfants sawvages: approches anthropologiques, pp. 156-157). No entanto, uma das ocorrências desse caso de Hesse na literatura é justamente o ano de 1304 (STRIVAY, Enfants sauvages: approches anthropologiques, p. 388). Serge Aroles, em seu livro, L'Enigme des enfants-loups: une certitude biologique mais un déni des archives 1304-1954, pode nos ajudar a esclarecer esse problema. "A famosa crônica dos beneditinos de Erfurt [...] menciona uma criança-lobo capturada em Hesse no ano de 1304, que elogiou a gentileza de seus lobos adotivos que o haviam criado aos três anos de idade, não para devorá-lo, mas para oferecer-lhe a melhor parte da caça e a posição mais quente durante o inverno". Aroles sustenta que houve uma confusão de datas por parte dos historiadores e cronistas e que, por isso, a criança-lobo de Hesse encontrada em 1344 realmente não existiu, pois sua descrição é a mesma da criança de 1304 e, ainda por cima, este caso foi reportado em um manuscrito também datado de 1304. "É relatado que a criança-lobo foi apresentada ao 'príncipe Henrique de Hesse'. A existência de dois homônimos que eram príncipes nesta área e nesta época é compatível com as duas falsas datas (1341-1344) e a verdadeira (1304). De fato, dois soberanos com mesmo nome autorizam o erro e a verdade, Henrique I e Henrique II reinaram, respectivamente, de 1275 a 1308 e de 1323 a 1376. [...] Deixemos de lado as incertezas: a criança-lobo 'de Hesse de 1344' (mencionada em 1583 por Pistorius) é aquela 'de Hesse de 1304' (relatada no manuscrito do mesmo ano), enquanto que a criança-lobo de Wetteravie (1344) desse mesmo autor, [...] é um caso distinto, para o qual são dadas precisões sobre a data e local de captura. Quanto àquela de 1341, que, por sua breve vida, não se faz presente nas análises manuscritas, nos permite pensar que, neste século XIV, as 'quatro' crianças-lobos eram apenas três” (AROLES, L'Enigme des enfants-loups, pp. 167169).

${ }^{29}$ ROUSSEAU, "Discours sur l'origine de l'inégalité", p. 196. 
inventor $^{30}$. Através da observação e imitação do comportamento intraespecífico os homens realizaram efetivamente seus primeiros progressos. A imitação, em vista disso, não se restringe necessariamente às observações dos comportamentos de outras espécies animais. Os homens são também objeto de observação e imitação. Como escreve Rousseau: "embora seus semelhantes não fossem para ele o que são para nós, e não tivesse muito mais trato com eles do que com os outros animais, eles não foram esquecidos em suas observações" ${ }^{31}$.

Essa possibilidade de imitação intraespecífica permite compreender a emergência, pré-social e propiciada pela perfectibilidade, de certas artes e técnicas rudimentares no estado de natureza, tal fato constitui aquilo que Guichet denominou de "cultura sem sociedade" 32 .

À guisa de conclusão, notamos que a perfectibilidade opera já no primeiro estado de natureza os mecanismos que vão distinguir o homem dos demais animais, antes mesmo do estabelecimento e da distinção das famílias e da "primeira revolução". Por isso, na primeira parte de seu Discurso, apesar de Rousseau animalizar o ser humano, não o reduz à animalidade, permanecendo o homem em seu estatuto próprio; assim, se o homem do puro estado de natureza pode ser, sob certos aspectos, considerado um animal, ele já é, sob outros, definitivamente homem - o que lhe permitirá ascender à cultura. A perfectibilidade "constitui a mediação necessária, situada do lado da natureza, entre esta natureza, de um lado, e a história e a cultura, de outro" 33 . Com ela o homem possui uma capacidade de variação quase que ilimitada, ao passo que o animal permanece encerrado em uma identidade fixa - o "animal é, ao término de alguns meses, o que ele será por toda sua vida" 34 . O constante movimento e a flexibilidade humanos contrastam com a imobilidade do animal, sempre petrificado em seu ser. Tal é a diferença que Rousseau estabelece entre a humanidade e a animalidade. A perfectibilidade introduz a possibilidade da história, da variabilidade e da não fixidez dessa natureza. De forma breve, a perfectibilidade, predicado que deveria imobilizar e fixar a natureza humana, mostra (e isso em sintonia com a liberdade) que não se pode compreender o homem como um ser dotado de uma natureza imóvel e fixa - algo análogo se passa na História natural de Buffon ${ }^{35}$-, mas sim como uma existência em constante movimento e ação. Em outras palavras, a perfectibilidade é a temporalização histórica da liberdade, uma temporalização apresentada por Rousseau ao longo de Discurso sobre a desigualdade com traços bastante dramáticos.

${ }^{30}$ ROUSSEAU, "Discours sur l'origine de l'inégalité", p. 160.

${ }^{31}$ ROUSSEAU, "Discours sur l'origine de l'inégalité", p. 167.

32 GUICHET, Rousseau: l'animal et l'homme, p. 252.

33 GUICHET, Rousseau: l'animal et l'homme, p. 250.

${ }^{34}$ ROUSSEAU, "Discours sur l'origine de l'inégalité", p. 142.

35 Algo semelhante pode ser visto em Buffon nos tomos IX (1761) e XIV (1766) de sua História natural. O homem "quis se acostumar a climas extremos e povoar as areias do sul e os gelos do norte" (BUFFON, "De la dégénération des animaux", p. 1016). Por esta razão, Buffon afirma que "há mais força, mais extensão e mais flexibilidade na natureza do homem do que na de qualquer outro ser" e que esta extensão provém das propriedades de sua alma. Como o homem é feito "para reinar sobre a Terra [...], parece que sua natureza se presta a todas as situações” possíveis (BUFFON, "Le Lion”, p. 844), não sendo de nenhuma região ou clima particular. 


\section{PERFECTIBILITY ACCORDING TO ROUSSEAU}

Abstract: The man in the pure state of nature begins his existence "with purely animal functions". In the first part of his Discourse on Inequality, as a matter of fact, Rousseau's effort consists in almost "animalizing" the human being, making him incapable of performing certain types of operations that the social or socialized man (endowed with an already developed mental apparatus) can do. However, although animalized, man maintains his own dignity and unique nature. The author never reduces the human behaviour to the animal. The aim of this article is to investigate the character of such a unique nature and to show that, against some interpreters, perfectibility (a sign of human distinction) already acts in the pure state of nature. In this sense, we cannot consider it as mere virtuality or as a potential faculty.

Keywords: Rousseau - Perfectibility - Humanity - Animality.

\section{REFERÊNCIAS BIBLIOGRÁFICAS}

AROLES, Serge. L'Enigme des enfants-loups. Paris: Publibook, 2007.

BEYSSADE, Jean-Marie. "Rousseau et la pensée du développement: Facultés virtuelles et développement". In: Entre forme et histoire: la formation de la notion de développement à l'âge classique. Présentation par Olivier Bloch, Bernard Balan et Paulette Carrire. Paris: MéridiensKlincksieck, 1988.

BUFFON. Euvres. Bibliothèque de la Pléiade. Paris: Gallimard, 2007.

DERRIDA, Jacques. De la Grammatologie. Paris: Éditions de Minuit, 1967.

DUCHEZ, Marie-Elisabeth. "Principe de la Mélodie et Origine des langues: un brouillon inédit de JeanJacques Rousseau sur l'origine de la mélodie". In: Revue de musicologie. Paris, 1974, Tome LX, n. 1-2, pp. 33-86.

GOLDSCHMIDT, Victor. Anthropologie et politique: les principes du système de Rousseau. Paris: Librairie philosophique J. Vrin, 1983.

GUICHET, Jean-Luc. Rousseau: l'animal et l'homme: L'animalité dans l'horizon anthropologique des Lumières. Paris: Les Éditions du Cerf, 2006.

LA METTRIE, Julien Offroy de. L’homme-Machine. Paris: Éditions Denoël/Gonthier, 1981.

MALSON, Lucien. Les enfants sauvages: Mythe et réalité; suivi de Mémoire et rapport sur Victor de l'Aveyron par Jean Itard. Paris: Éditions 10/18, 1964.

MASTERS, Roger. The Political Philosopby of Rousseau. Princeton: Princeton University Press, 1968.

MONTAIGNE. Essais. Tome I. Paris: GF Flammarion, 1969. 
RADICA, Gabrielle. L'bistoire de la raison: anthropologie, morale et politique chez Rousseau. Paris: H. Champion, 2008.

ROBERT, Thomas. "Rousseau et les Pongos". Revue de primatologie [En ligne], 4, 2012, document 3, mis en ligne le 15 décembre 2012, Consulté le 25 novembre 2015. URL: http://primatologie.revues.org/1009.

ROUSSEAU. Du Principe de la mélodie. In: Wokler, Robert. Rousseau on society, politics, music and language [Texte imprimé]: an historical interpretation of his early writings. New York: Garland, 1987, pp. 436482.

ROUSSEAU. CEuvres Completes de Jean-Jacques Rousseau. Ed. Bernard Gagnebin e Marcel Raymond. Paris: Gallimard, 1959-1995. 5 volumes. (Col. Bibliothèque de la Pléiade).

STAROBINSKI, Jean. Jean-Jacques Rousseau: a transparência e o obstáculo, seguido de sete ensaios sobre Rousseau. São Paulo: Companhia das Letras, 1991.

STRIVAY, Lucienne. Enfants sauvages: approches anthropologiques. Paris: Éditions Gallimard, 2006. 